\title{
An In Vitro Study of Effect of Beveling of Enamel on Microleakage and Shear Bond Strength of Adhesive Systems in Primary and Permanent Teeth
}

\author{
Shagun Patanjali ${ }^{1}$, Anshul Arora ${ }^{2}$, Ashtha Arya ${ }^{3}$, Mandeep S Grewal ${ }^{4}$
}

\begin{abstract}
Aim and objectives: This in vitro study evaluated the effect of beveling of enamel on microleakage and shear bond strength of total-etch adhesive system: prime and bond NT and self-etch: adhesive system: XENO V in primary and permanent teeth.

Materials and methods: A total of 120 extracted human molars ( 60 primary and 60 permanent) were selected for the study. For microleakage examination, a sample size of 40 was chosen. Two rectangular slots of equal dimensions were prepared on the buccal surface of each tooth and a bevel was given on either of the slots. Each slot was restored using a composite resin with prior application of the selected bonding agent following which all the samples were soaked in $1 \%$ methylene blue dye for 48 hours. Then each tooth was sectioned horizontally and evaluated. The remaining 80 samples were subjected to the shear bond strength test. Class II cavities of standard dimension were prepared and bevel was given on each sample following which selected bonding agent was applied and restored with a composite resin. The specimens were placed in a fixture and the shear bond strength was determined using the universal testing machine.

Results: With respect to microleakage, the least was exhibited by beveled preparations in permanent teeth using the self-etch adhesive system and the highest shear bond strength was exhibited by beveled preparations using the total-etch adhesive system in permanent teeth.

Conclusion: Beveling of enamel improved the marginal integrity and shear bond strength of self-etch and total-etch adhesive systems in both primary and permanent teeth.
\end{abstract}

Keywords: Beveling, Bonding agent, Microleakage, Self-etch adhesive system, Shear bond strength, Total-etch adhesive system. International Journal of Clinical Pediatric Dentistry (2019): 10.5005/jp-journals-10005-1623

\section{INTRODUCTION}

Adhesion mechanisms are the focus of research into developing an optimal adhesive model. The basic mechanism of bonding to enamel and dentin is essentially an exchange process involving the replacement of minerals removed from the hard dental tissue by resin monomers that upon setting become micromechanically interlocked in the created porosities. ${ }^{1}$ Recent tooth restorative adhesives can be classified into total-etch and self-etch bonding agents depending on the number of steps employed for bonding. ${ }^{2}$

Besides the use of dental adhesives, beveling of enamel is suggested for improving the marginal integrity and durability while using composite restorative materials.,

Laboratory in vitro tests such as bond strength measurement and microleakage evaluation are vital screening tests that serve to predict the clinical behavior of bonding systems. ${ }^{5}$

The purpose of this in vitro study is to study the effect of beveling of enamel on microleakage and shear bond strength of total-etch adhesive system: prime and bond NT and self-etch: adhesive system: XENO V in primary and permanent teeth.

\section{Materials and Methods}

The study was conducted at the Department of Pedodontics and Preventive Dentistry in collaboration with the Department of Oral Pathology, at I.T.S.-Centre for Dental Studies and Research, Ghaziabad, and I.T.S. Engineering College, Greater Noida.

A total of 120 extracted human molars (60 primary and 60 permanent) were selected for the study. The coronal portion and the buccal surface of the teeth selected were intact and the teeth
1Department of Pedodontics and Preventive Dentistry, Faculty of Dental Sciences, SGT University, Gurugram, Haryana, India

${ }^{2-4}$ Department of Conservative Dentistry and Endodontics, SGT University, Gurugram, Haryana, India

Corresponding Author: Shagun Patanjali, Department of Pedodontics and Preventive Dentistry, Faculty of Dental Sciences, SGT University, Gurugram, Haryana, India, Phone: +91 9971834354, e-mail: shagunpatanjali@gmail.com

How to cite this article: Patanjali S, Arora A, et al. An In Vitro Study of Effect of Beveling of Enamel on Microleakage and Shear Bond Strength of Adhesive Systems in Primary and Permanent Teeth. Int J Clin Pediatr Dent 2019;12(3):205-210.

Source of support: Nil

Conflict of interest: None

were free of any enamel/dentin defects. Teeth with fractured crowns, with any kind of enamel/dentin defects, and teeth with restorations were excluded from the study sample. After obtaining the samples, surface debridement was done by ultrasonic or hand scalers and, subsequently, the samples were autoclaved. If necessary, the samples were stored in $10 \%$ formalin. The distribution of the samples was done according to the following criteria:

- Type of tooth (primary/permanent)

- Parameter (microleakage/shear bond strength)

- Type of adhesive system (self-etch/total-etch)

- Type of margin (beveled/nonbeveled)

The samples were distributed according to the groups assigned as in Table 1.

(O) The Author(s). 2019Open Access This article is distributed under the terms of the Creative Commons Attribution 4.0 International License (https://creativecommons. org/licenses/by-nc/4.0/), which permits unrestricted use, distribution, and non-commercial reproduction in any medium, provided you give appropriate credit to the original author(s) and the source, provide a link to the Creative Commons license, and indicate if changes were made. The Creative Commons Public Domain Dedication waiver (http://creativecommons.org/publicdomain/zero/1.0/) applies to the data made available in this article, unless otherwise stated. 
Group I: microleakage examination with a sample size of 40 (20 primaries and 20 permanent molars). Two rectangular slots of equal dimensions (mesiodistal width $-2 \mathrm{~mm}$, occlusogingival height $-3 \mathrm{~mm}$, and depth of the preparation $-2 \mathrm{~mm}$ ) were prepared on the buccal surface of each tooth using a $169 \mathrm{~L}$ straight fissure diamond bur. A bevel was given on either of the slots using a fissuroplasty bur. This yielded 40 slot preparations in 20 primary teeth and 40 in the remaining 20 permanent teeth. Total-etch adhesive (prime and bond NT) was applied in both the slots of 10 primary and 10 permanent teeth, and self-etch adhesive (Xeno $\mathrm{V}$ ) in the remaining 10 primary and 10 permanent teeth and then light cured. All the preparations were restored with the CeramX (Dentsply) resin composite and polished using polishing discs to remove any marginal composite flash. The teeth were then stored in distilled water at $21^{\circ} \mathrm{C}$ and subjected to thermocycling in a water bath. The surface of the teeth leaving up to $1.5 \mathrm{~mm}$ around the restoration was coated with a layer of nail varnish. The teeth were then soaked in $1 \%$ methylene blue dye for 48 hours. To evaluate the dye penetration, the excess dye was rinsed off with distilled water. Each tooth was sectioned horizontally with a sectioning disc mounted on a slow-speed handpiece, to obtain four samples per tooth, each sample containing either the total-etch or self-etch adhesive system with a beveled and a nonbeveled preparation. This resulted in four microleakage measurements per tooth. The cut sections were examined for marginal leakage at the toothcomposite interface (at the cavity margin) under a stereomicroscope under different magnifications. Each of the sample sections was given a score according to the microleakage scoring criteria given by Munshi et al.: 6

Group II: shear bond strength determination with a sample size of 80 (40 primaries and 40 permanent teeth). Class II cavities of standard dimension, $4 \mathrm{~mm}$ buccolingual, $4 \mathrm{~mm}$ occlusogingival, and $2 \mathrm{~mm}$ mesiodistal, with facial and lingual walls straight and parallel to each other, were prepared on each of the primary and permanent teeth. Bevel was given during the preparation to specific teeth according to the groups assigned (Table 1). In 40 samples (20 primary and 20 permanent), Xeno $V$ was applied and prime and bond NT was applied on the remaining 40 samples ( 20 primary and 20 permanent), light cured and restored with the Ceram X composite resin. The specimens were placed in a fixture that positioned them for loading at an angle of $45^{\circ}$. For this purpose, metallic rings with a 1- and 2-inch high diameter were used. The upper half of the ring was cut at a $45^{\circ}$ angle to the long axis of the ring. The rings were filled with an auto-polymerizing acrylic resin up to their uppermost margin. All the specimens were placed in the rings, exposing the coronal portion and the roots covered with the acrylic resin. The specimens were placed perpendicular to the acrylic resin surface.
Score 0 no marginal leakage at all

Score 1 shows marginal leakage only covering half of one wall of the cavity

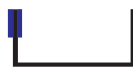

Score 2 shows marginal leakage covering one wall of the cavity preparation

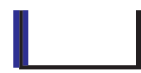

Score 3 shows marginal leakage covering one wall and half of the floor of the cavity preparation

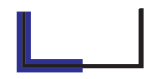

Score 4 shows marginal leakage covering one wall and entire wall of the cavity preparation

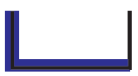

Score 5 shows marginal leakage covering one wall, the entire floor and half of the second wall of the cavity preparation

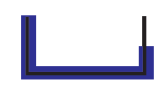

Score 6 shows marginal leakage covering both the walls as well as the floor of the cavity preparation

The mounted specimens in rings were stored in distilled water until testing was performed. The bond strength between the restorative material and tooth surface was measured in the shear mode with the universal testing machine. The specimens were mounted in the metallic jig, while a straight knife-edge rod $2 \mathrm{~mm}$-wide was applied at the tooth-restoration interface. This resulted in a shear force at a $45^{\circ}$ angle to the tooth surface. A load was applied until restoration failure occurred. The bond strength was recorded in Newtons. The total bonded surface area of the proximal box cavity preparation was $40 \mathrm{~mm}^{2}$, and it was calculated as the sum of the surface area of the gingival wall $\left(8 \mathrm{~mm}^{2}\right)$, facial wall $\left(8 \mathrm{~mm}^{2}\right)$, lingual wall $\left(8 \mathrm{~mm}^{2}\right)$, and axial wall $\left(16 \mathrm{~mm}^{2}\right)$. Loads were converted to MPa by dividing the loads in Newton by the total bonded surface area:

$$
\text { Loads }(\mathrm{MPa})=\frac{\text { Load }(\text { Newtons })}{\text { Total bonded surface area }}
$$

The differences in microleakage and shear bond strength between the eight subgroups were analyzed using biostatistical parameters. The differences in microleakage and shear bond strength between the eight subgroups were analyzed using a

Table 1: Division according to variables

\begin{tabular}{lllll}
\hline Group number & $\begin{array}{l}\text { Variable total etch or self-etch } \\
\text { (beveled/nonbeveled) }\end{array}$ & No. of teeth & $\begin{array}{l}\text { Number of preparations } \\
\text { (beveled/nonbeveled) }\end{array}$ & $\begin{array}{l}\text { Total sample obtained } \\
\text { (beveled/nonbeveled) }\end{array}$ \\
\hline 1A (i) & Total etch, beveled/nonbeveled & 10 & $10 / 10$ & $20 / 20$ \\
(ii) & Self-etch, beveled/nonbeveled & 10 & $10 / 10$ & $20 / 20$ \\
IB (i) & Total etch, beveled/nonbeveled & 20 & $10 / 10$ & $10 / 10$ \\
(ii) & Self-etch, beveled/nonbeveled & 20 & $10 / 10$ & $10 / 10$ \\
IIA (i) & Total etch, beveled/nonbeveled & 10 & $10 / 10$ & $20 / 20$ \\
(ii) & Self-etch, beveled/nonbeveled & 10 & $10 / 10$ & $20 / 20$ \\
IIB (i) & Total etch, beveled/nonbeveled & 20 & $10 / 10$ & $10 / 10$ \\
(ii) & Self-etch, beveled/nonbeveled & 20 & $10 / 10$ & $10 / 10$ \\
\hline
\end{tabular}


Table 2: Mean values of microleakage in the subgroups using two-way ANOVA

\begin{tabular}{llll}
\hline Group & Microleakage & Mean & $\begin{array}{l}\text { Standard } \\
\text { deviation }\end{array}$ \\
\hline Permanent beveled SE & 0.75 & 0.9 & 1.236 \\
Permanent nonbevel SE & 1.05 & 0.9 & 1.236 \\
Permanent bevel TE & 1.15 & 1.22 & 1.476 \\
Permanent nonbevel TE & 1.3 & 1.22 & 1.476 \\
Primary bevel SE & 2.0 & 2.45 & 1.974 \\
Primary nonbevel SE & 2.9 & 2.45 & 1.974 \\
Primary bevel TE & 3.1 & 3.45 & 2.075 \\
Primary nonbevel TE & 3.8 & 3.45 & 2.075 \\
\hline
\end{tabular}

SE, self-etch adhesive; $\mathrm{TE}$, total-etch adhesive
Table 3: Statistical analysis values for microleakage obtained from analysis of variance of the three variables (adhesive, margin, and tooth type)

\begin{tabular}{llll}
\hline Tooth type & Interaction type & F-statistic & $p$-value \\
\hline Primary & TE vs SE & 4.954 & $0.029^{*}$ \\
& B vs NB & 3.171 & $0.079^{*}$ \\
\multirow{3}{*}{ Permanent } & B-NB vs TE-SE & 0.05 & $0.824^{*}$ \\
& TE vs SE & 1.119 & $0.293^{*}$ \\
& B vs NB & 0.536 & $0.466^{*}$ \\
& B-NB vs TE-SE & 0.06 & $0.808^{*}$ \\
\hline
\end{tabular}

${ }^{* *} p$-value $<0.001$, significant

${ }^{*} p$-value $>0.001$, nonsignificant

Table 4: Percentage distribution of samples in the subgroups showing microleakage

\begin{tabular}{|c|c|c|c|c|c|c|c|c|c|}
\hline Level of leakage & Scoring & PRI TEB & PRI TENB & $P R I S E B$ & PRI SENB & PERM TEB & PERM TENB & PERM SEB & PERM SENB \\
\hline No leakage & 0 & 20 & - & 35 & 10 & 50 & 50 & 70 & 55 \\
\hline In enamel & 1 & 10 & 20 & 10 & 15 & 5 & - & - & - \\
\hline \multirow[t]{5}{*}{ In dentin } & 2 & 5 & 15 & 20 & 25 & 30 & 40 & 20 & 30 \\
\hline & 3 & 15 & 5 & 10 & 10 & - & - & 5 & 15 \\
\hline & 4 & 20 & 15 & 10 & 20 & 10 & 5 & 5 & - \\
\hline & 5 & 15 & 15 & 10 & 5 & - & - & - & - \\
\hline & 6 & 15 & 30 & 5 & 15 & - & 5 & - & - \\
\hline Total \% samples & Score 2-6 & 70 & 80 & 55 & 75 & 40 & 50 & 30 & 45 \\
\hline
\end{tabular}

in dentin

PRITEB, primary total-etch beveled; PRI TENB, primary total-etch nonbeveled; PRI SEB, primary self etch beveled; PRI SENB, primary self-etch nonbeveled; PERM TEB, permanent total-etch beveled; PERM TENB, permanent total-etch nonbeveled; PERM SEB, permanent self-etch beveled; PERM SENB, permanent self-etch nonbeveled

two-way ANOVA, and the Fischer exact test was used to determine if there were any significant differences in microleakage (as mentioned in results in Tables 2 to 4 and Fig. 1) and shear bond strength (Tables 5 and 6 and Fig. 2) among the subgroups.

\section{Results}

The results of the present study indicate that beveling of enamel improved the marginal integrity and shear bond strength of self-etch and total-etch adhesive systems in both primary and permanent teeth. Enamel beveling could not completely eliminate

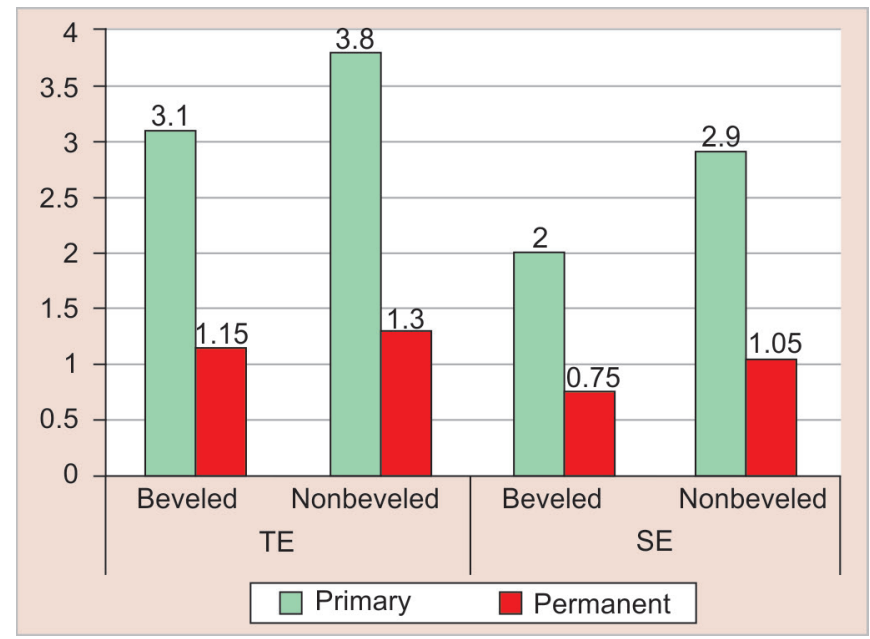

Fig. 1: Comparison of microleakage values amongst subgroups
Table 5: Mean values of shear bond strength in the subgroups using two-way ANOVA

\begin{tabular}{llll}
\hline Tooth type & & Total-etch & Self-etch \\
\hline Primary & Beveled & 16.16 & 11.48 \\
& Non beveled & 14.43 & 10.42 \\
& Mean & 15.3 & 10.95 \\
& SD & 1.412 & 1.149 \\
Permanent & Beveled & 21.94 & \\
& Nonbeveled & 20.44 & 14.56 \\
& Mean & 21.19 & 13.85 \\
& SD & 2.103 & 1.21 \\
& & $p$ value $<0.001$ & \\
\hline
\end{tabular}

Table 6: Statistical analysis values for shear bond strength obtained from analysis of variance of the three variables (adhesive, margin, and tooth type)

\begin{tabular}{llcc}
\hline Tooth type & Interaction type & F-statistic & $p$-value \\
\hline Primary & TE vs SE & 160.85 & $<0.001^{* *}$ \\
& B vs NB & 16.66 & $<0.001^{* *}$ \\
& B-NB vs TE-SE & 0.96 & $0.335^{*}$ \\
Permanent & TE vs SE & 149.26 & $<0.001^{* *}$ \\
& B vs NB & 3.76 & $0.06^{*}$ \\
& B-NB vs TE-SE & 0.47 & $0.495^{*}$ \\
\hline
\end{tabular}

${ }^{* *} p$ value $<0.001$, significant

${ }^{*} p$ value $>0.001$, nonsignificant 


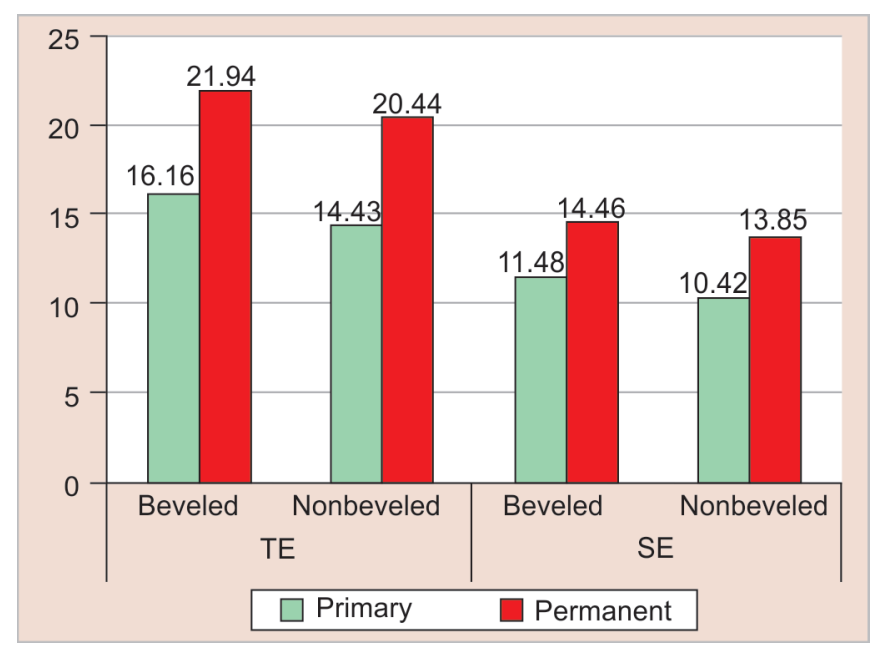

Fig. 2: Comparison of shear bond strength values among subgroups

microleakage in either of the adhesive systems used in the study. However, beveling of enamel in permanent teeth using the self-etch adhesive system gave the best results with respect to marginal integrity as more than $50 \%$ of the samples (70\%) exhibited no microleakage at all and only $30 \%$ exhibited microleakage. In contrast, all the samples in the total-etch adhesive system in primary teeth with enamel beveling exhibited microleakage. In addition, the microleakage extending only up to enamel varied from 10 to $20 \%$ in primary teeth to 0 to $5 \%$ in permanent teeth in comparison to microleakage extending up to dentin which varied from 55 to $80 \%$ in primary teeth to 30 to $50 \%$ in permanent teeth.

In the present study, enamel beveling improved the shear bond strength of total-etch and self-etch adhesive systems in both primary and permanent teeth as compared to the nonbeveled preparations.

The highest shear bond strength (21.94 MPa) was exhibited by the total-etch adhesive system with beveled margins in permanent teeth and the least shear bond strength was exhibited by the selfetch adhesive system without a bevel in primary teeth (10.42 MPa).

\section{Discussion}

Successful adhesion to hard tissues is a fundamental requirement before placement of resin-based composites. The foundation for adhesion of restorative materials was laid in 1955 when Buonocore reported that acids could be used to alter the surface of enamel to render it more receptive to adhesion. ${ }^{7}$ The acid etch bonding of composite resin to enamel has been proven to be an effective method to enhance the enamel-restoration interface by increasing its strength and decreasing leakage. Good adhesion between the adhesive resin and the dental hard tissue is of utmost importance for the success of a composite restoration. This can be judged in terms of its strength and marginal integrity which affect the durability of the interface between the adhesive and the substrate (enamel/dentin). Microleakage has been defined as the marginal permeability to bacterial, chemical, and molecular invasion at the tooth/material interface and is the result of a breakdown of the tooth-restoration interface, causing discoloration, recurrent caries, pulpal inflammation, and possible restoration replacement. ${ }^{8} \mathrm{~A}$ microleakage test, combined with thermocycling, is a useful in vitro method to assess sealing performance of an adhesive restoration.
Microleakage can be demonstrated by using bacteria, compressed air, chemical and radioactive tracers, electrochemical investigations, scanning electron microscopy, and dye penetration. ${ }^{9}$

In our study, methylene blue dye was used to evaluate microleakage because it has displayed better penetration results than eosin or the radioisotope tracers, $\mathrm{Ca}^{45}$-labeled calcium chloride, $\mathrm{C}^{14}$-labeled urea, and $\mathrm{I}^{125}$-labeled albumin. ${ }^{10}$ The in vitro study evaluated the effect of enamel beveling on the microleakage and shear bond strength using two different types of adhesive systems (total etch: prime and bond NT and self-etch: XENO $\mathrm{V}$ ) in primary and permanent teeth. The results of this study demonstrated that enamel beveling and the self-etch adhesive system could eliminate microleakage in 35\% of primary and $70 \%$ in permanent teeth. Microleakage limited to enamel varied from 10 to $20 \%$ in primary teeth to 0 to $5 \%$ in permanent teeth. The use of an enamel bevel significantly $(p<0.001)$ resulted in a decrease in microleakage using the same adhesive system and the same tooth substrate (primary/permanent). Beveling results in the removal of the aprismatic superficial enamel layer, which is also richer in the fluoride content, favoring the acid etching; increasing the free surface energy, favoring surface wetting; enhancing the surface area of exposed enamel; providing better marginal seal; better esthetic results; and improving the material retention. ${ }^{4}$

Extension of enamel cavosurface bevel helps to improve the enamel peripheral seal by preventing the formation of marginal gaps due to polymerization contraction stresses at the resin-dentin interface, thereby improving the performance of restorations. ${ }^{11}$ An additional benefit of beveling is that the bevel provides a greater marginal surface to compensate for polymerization shrinkage, which will help to reduce microleakage. Swanson et al. supported that beveling the margins of all nonstress-bearing composite restorations reduces marginal microleakage in teeth, and margin beveling has a greater effect on minimizing microleakage than the type of adhesive used. ${ }^{3}$

Similar results have been demonstrated in previous studies evaluating microleakage with the placement of marginal bevel in composite restorations in primary ${ }^{12}$ and permanent ${ }^{13,14}$ teeth, while a few ${ }^{15}$ have shown no significant difference in microleakage at beveled and nonbeveled margins.

The total-etch adhesive system showed higher microleakage than the self-etch system. Such a finding may be attributed to the relatively aggressive nature of total-etch bonding systems. The bonding agent copolymerizes with the primer to form an intermingled layer of collagen fibers and resin called the "hybrid layer," "resin reinforced zone," or "resin-infiltrated layer." This hybrid layer, which was first described by Nakabayashi et al., ${ }^{16}$ has been considered the most important factor for ensuring a good bond between resin and dentin. With the relatively aggressive total-etch technique, dentin may also be demineralized to a depth that might be inaccessible to complete resin impregnation. If so, a collagenous band at the base of the hybrid layer not impregnated by resin would dramatically weaken the resin-dentin bond and, consequently, the bond durability. More signs of incomplete resin penetration were observed as a microporous dentin zone present at the base of the hybrid layer. The porous zone was stated to be a pathway for nanoleakage of fluids. ${ }^{17}$ It was believed that these nanoleakage channels could provide a pathway for water, enzymes, acid, and bacterial products to enter into the bonded interface resulting in the degradation of uncoated collagen fibrils leading to premature failure of dentin bonding. ${ }^{16}$ In self-etch adhesive systems, there 
is no discrepancy between the demineralization depth and the resin infiltration depth, since both processes occur at the same time. Besides simplification in terms of the number of clinical steps involved, the rationale of these newer adhesive systems is to superficially demineralize dentin and simultaneously penetrate it with monomers, which can be polymerized in situ. ${ }^{18}$

However, a few studies ${ }^{3,9}$ have reported that total-etch adhesive systems demonstrated better sealing ability than self-etch adhesive systems.

Achievement of strong micromechanical bonding depends on the depth of monomer penetration into the demineralized enamel and dentin. ${ }^{19}$ Prime and bond NT (total-etch adhesive system) due to phosphoric acid as the etchant exhibits a $\mathrm{pH}$ of 0.6 with a hybrid layer thickness of approximately 3-5 $\mu \mathrm{m}$, while XENO V (self-etch adhesive system) has a $\mathrm{pH}$ of 1.8 with a hybrid layer thickness of approximately $0.5-2 \mu \mathrm{m} .{ }^{20}$ The differences of thickness could be due to a number of factors such as differences in viscosity of the adhesive systems, filled vs unfilled primer/adhesives, and variations in the number of coats and application techniques as indicated by the manufacturers. ${ }^{9}$ Scanning electron microscope studies revealed a shallow and less defined etching pattern considered as deficient penetration of self-etching primer suggesting that the etching effect was an important factor in the bonding of self-etching adhesives. ${ }^{21}$ The enamel etching pattern caused by self-etching adhesives is less deep and appears less retentive compared to the etching pattern of phosphoric acid treatment. ${ }^{22}$

Prime and bond NT is an acetone-based adhesive, whereas XENO V is a water-based adhesive. Total-etch adhesive systems that contain acetone require a wet bonding technique. For adhesives that contain ethanol and water, a dry bonding technique is a key to delivering good bonding performance. The wet bonding technique is technique sensitive in terms of water balance, which may cause overwetting the etched substrate if water is not effectively removed. Thus, improper application can adversely affect the marginal adaptation and bond strength accounting for higher microleakage of prime and bond $\mathrm{NT}^{23}$

Microleakage may be caused by a variation in physical properties like polymerization shrinkage, coefficient of thermal expansion, and modulus of elasticity between the tooth and the composite resin restoration.

In this study, we evaluated the effect of beveling of enamel on the shear bond strength of the two types of adhesive systems used. These in vitro bonding tests were effective methods in understanding the physical strength of adhesive systems and were also important tools in predicting and developing the clinical performance of adhesive systems. The advantage of in vitro measurement of the bond strength test method was being relatively simple with respect to specimen preparation, equipment required, and test setup, but the main criticism was that it measured the cohesive strength of the material being bonded or the substrate (or both), rather than the bond strength of the adhesive interface. This was attributed to the nature of the stresses generated and their distribution within the adherence zone, and the relatively low bond strengths obtained might be explained by differences in material combinations, test set-up, and operator factors. ${ }^{24}$

Also, studies reported that despite its well-known limitations, the shear bond test set-up had been the most commonly employed laboratory technique for evaluating the bond strength of adhesives. In the present study, enamel beveling did improve the shear bond strength of total-etch and self-etch adhesive systems in both primary and permanent teeth as compared to the nonbeveled preparations.
It has been suggested that the minimum bond strength of 17-20 MPa is needed to resist contraction forces of resin composite materials, for enamel and dentin. ${ }^{24}$ Clinical experiences confirm that this bond strength is sufficient for successful retention of resin restoration.

In our study, the total-etch adhesive system exhibited a mean shear bond strength of $21.19 \pm 2.10 \mathrm{MPa}$ with $21.94 \pm 2.02 \mathrm{MPa}$ in beveled preparations and $20.44 \pm 1.99 \mathrm{MPa}$ in nonbeveled preparations in permanent teeth. This implies that only the shear bond strength of the total-etch adhesive system with enamel bevel and without enamel bevel exhibited optimum values more than 20 MPa which is needed to resist contraction forces of resin composite materials, for enamel and dentin. None of the adhesive systems used in primary teeth with and without enamel bevel along with the self-etch adhesive system in permanent teeth exhibited optimum shear bond strength values of 17-20 MPa. Although self-etch adhesives have an upper hand over total-etch adhesives in terms of simplicity of clinical application and lesser time consumption but are inferior in terms of bond strength as compared to totaletch systems which can be attributed to their semipermeability, incorporation of smear layer, shorter resin tag formation, residual acidity, and hydrolytic instability. ${ }^{19}$

The adhesives contain a hydrophilic primer 2-hydroxyethyl methacrylate (HEMA) that utilizes acetone (prime and bond NT), alcohol, and/water (XENO V) as solvents. These solvents act as chasers as they carry the resin primer into the demineralized substrate by displacing water from the collagen network and occupation of this demineralized substrate is responsible for forming the hybrid layer or the interdiffusion zone. In the totaletch adhesive system, following etching with phosphoric acid, the etchant is washed off followed by drying with compressed air prior to adhesive application. These solvents compete with water present at the tooth-restoration interface by promoting a union of water molecules and subsequently displacing water. Prime and bond NT permits better penetration of the monomer due to an additional step of drying with compressed air in comparison to self-etch adhesives. This removal of water from collagen fibrils may stabilize the structure by increasing the amount of interaction of weak forces between adjacent collagen molecules. In addition, this may lead to the formation of hydrogen bonds between collagen molecules that were previously bonded to water molecules, thus, increasing the bond strength of total-etch adhesive systems. ${ }^{9}$

In our study, prime and bond NT exhibited higher shear bond strength but higher microleakage as compared to XENO V. The bond strength of an adhesive does not always accurately predict its sealing ability. Thus, adhesives with high bond strength may still exhibit undesirable levels of microleakage. ${ }^{25}$ This antagonistic performance of prime and bond NT may be due to the fact that in our study, bond strength and microleakage tests were performed on separate teeth which differed in terms of the cavity preparation and their location on the tooth surface. The differences in microleakage and shear bond strength values for the two substrates in our study can be attributed to the chemical, morphological, and structural differences between primary and permanent teeth.

The increased thickness of dentine ${ }^{26}$ increased mineralization ${ }^{27}$ with increased calcium and phosphorus concentration in peritubular and intertubular dentin, ${ }^{26}$ and increased surface moisture ${ }^{28}$ in permanent teeth as compared to primary teeth have been the probable causes for reduced bond strength in primary teeth. 
Nor et al. ${ }^{29}$ demonstrated that the hybrid layer in primary teeth is comparatively thicker than in permanent teeth for the same period of conditioning. Uekusa et al. ${ }^{30}$ observed that the peritubular dentin was demineralized rapidly during acid treatment. It was thicker for primary than permanent dentin and a further decrease in the bonding substrate might occur. They also observed that acids used to condition the dentin surface removed the smear layer more rapidly from primary teeth than permanent teeth suggesting that the composition of smear layer being related directly to the composition of the underlying dentin which can be reasonably explained on the basis of difference in chemical composition of primary tooth dentin and permanent tooth dentin.

To improve the clinical performance and longevity of resin restorations in terms of microleakage and shear bond strength, enamel beveling is suggested in both primary and permanent teeth.

\section{Conclusion}

The present study demonstrated that beveling of enamel in permanent teeth using the self-etch adhesive system gave the best results among the eight groups compared in terms of marginal integrity as microleakage could be eliminated in $70 \%$ of the samples. The highest shear bond strength (21.94 MPa) was exhibited by the total-etch adhesive system with beveled margins in permanent teeth and least shear bond strength was exhibited by the self-etch adhesive system without a bevel in primary teeth (10.42 MPa). In other words, beveling of enamel using the total-etch adhesive system in permanent teeth could reach the minimum value of 17-20 MPa which was needed to resist contraction forces of resin composite materials for enamel and dentin. All other groups showed bond strength values less than $17 \mathrm{MPa}$.

Although the statistically significant difference between the beveled and nonbeveled preparations with the two adhesive systems in primary and permanent teeth was seen only with respect to shear bond strength but not with respect to microleakage in the present study.

\section{References}

1. Peumans M, Kanumilli $P$, et al. Clinical effectiveness of contemporary adhesives: a systematic review of current clinical trials. Dent Mater 2005;21:864-881. DOI: 10.1016/j.dental.2005.02.003.

2. Perdigao J, Geraldeli S, et al. Total-etch vs self-etch adhesive effect on postoperative sensitivity. J Am Dent Assoc 2003;134:1621-1629. DOI: 10.14219/jada.archive.2003.0109.

3. Swanson TK, Feigal RJ, et al. Effect of adhesive systems and bevels on enamel margin integrity in primary and permanent teeth. Pediatr Dent 2008;30(2):134-140.

4. De Souza FH, Rocha AC, et al. Influence of Adhesive System and Bevel Preparation on Fracture Strength of Teeth Restored With Composite Resin. Braz Dent J 2010;21(4):327-331. DOI: 10.1590/S010364402010000400007.

5. Bengtson $C R G$, Bengtson $A L$, et al. Do the origins of primary teeth affect the bond strength of a self-etching adhesive system to dentin? Braz Oral Res 2010 Jul-Sep;24(3):355-360. DOI: 10.1590/S180683242010000300016.

6. Puppala R, Hegde A, et al. Laser and light-cured composite resin restorations-in vitro comparison of isotope and dye penetrations. J Clin Pediatr Dent 1996;20(3):213-218.

7. Swift EJ. Dentin/enamel adhesives: review of literature. Pediatr Dent 2002;24:456-461.

8. Owens BM, Johnson WW, et al. Marginal Permeability of self etch and total etch adhesive systems. Oper Dent 2006 Jan-Feb;31(1):60-67. DOI: 10.2341/04-185.
9. Arias VG, Campos IT, et al. Microleakage Study of Three Adhesive Systems. Braz Dent J 2004;15(3):194-198. DOI: 10.1590/S010364402004000300006.

10. Kumari M, Taneja S, et al. Comparative Evaluation of Microleakage of One Self-Etch and Two Total-Etch Bonding Systems -An In Vitro Study. J Ind Dent Assoc 2011;5(6):679-682.

11. Perdigao J, Swift JE. Fundamental concepts of enamel and dentin adhesion. Roberson TM, Heymann HO. Art and science of operative dentistry, 5th ed. Philadelphia: Mosby, 2006; pp. 245-279.

12. Nozaka K, Suruga Y, et al. Microleakage of composite resincavities of upper primary molars. Int J Paediatr Dent 1999;9(3):185-194. DOI: 10.1046/j.1365-263x.1999.00135.x.

13. Opdam NJM, Roeters JJM, et al. Necessity of bevels for box only Class II composite restorations. J Prosthet Dent 1998;80:274-279. DOI: 10.1016/S0022-3913(98)70127-1.

14. Erikson HM, Buonocore MG. Marginal leakage with different composite restorative materials in vitro. J Oral Rehab 1976;3(4):315322.

15. Santini A, Ivanovic $V$, et al. Influence of marginal bevels on microleakage around class $V$ cavities bonded with seven self-etching agents. Am J Dent 2004 Aug;17(4):257-261.

16. Xiong $Y$, Chen J, et al. Evaluation of shear bond strength and microleakage of deproteinized dentin bonded with three total etch adhesive systems. Int Chin J Dent 2006;6:82-88.

17. Veerakumar R, Prabhu MN, et al. A Comparative Evaluation of Interfacial Micromorphology of Two Adhesive Systems In Primary and Permanent Teeth-A SEM Evaluation. Indian J Multidiscip Dent 2011;1(6):321-324.

18. Atash R, Abbeele AV. Sealing Ability of New Generation Adhesive Systems in Primary Teeth: An In Vitro Study. Pediatr Dent 2004;26(4):322-328.

19. Hegde MN, Bhandary S. An evaluation and comparison of shear bond strength of composite resin to dentin, using newer dentin bonding agents. J Conserv Dent 2008;11(2):71-75. DOI: 10.4103/09720707.44054 .

20. Grewal MS, Grewal SB, et al. Bonding Systems: Present and Future. J Ind Dent Assoc 2011;5(5):656-658.

21. Abo T, Uno S, et al. Comparison of bonding efficacy of an all-inone adhesive with a self-etching primer system. Eur J Oral Sci 2004;112:286-292. DOI: 10.1111/j.1600-0722.2004.00126.x.

22. Khosravi K, Mousavi M. Effect of pre-etching on sealing ability of two current self-etching adhesives. J Res Med Sci 2005;10(3):150-155.

23. Baygin $\mathrm{O}$, Korkmaz $\mathrm{H}$, et al. Effects of different types of adhesive systems on the microleakage of compomer restorations in Class $\mathrm{V}$ cavities prepared by Er,Cr:YSGG laser in primary teeth. Dent Mater J 2012;31(2):206-214. DOI: 10.4012/dmj.2011-133.

24. Can-Karabulut DC, Oz FT, et al. Adhesion to Primary and Permanent Dentin and a Simple Model Approach. Eur J Dent 2009;3:32-41.

25. Waldman GL, Vaidyanathan TK, et al. Microleakage and Resinto-Dentin Interface Morphology of Pre-Etching vs Self-Etching Adhesive Systems. Open Dent J 2008 Nov;28(2):120-125. DOI: $10.2174 / 1874210600802010120$.

26. Courson F, Bouter $D$, et al. Bond strengths of nine current dentine adhesive systems to primary and permanent teeth. J Oral Rehab 2005;32:296-303. DOI: 10.1111/j.1365-2842.2004.01412.x.

27. Johnsen DC. Comparison of primary and permanent teeth. Avery JK. Oral Development and Histology. Philadelphia (PA): BC Decker, 1987; pp. 180-190.

28. Burrow MF, Takahurah NM, et al. The influence of age and depth of dentin on bonding. Dent Mater 1994;10:241-246. DOI: 10.1016/01095641(94)90068-X.

29. Nor JE, Fcigal RJ, et al. Dentin Bonding: SEM Comparison of the resin-dentin interface in primary and permanent teeth. J Dent Res 1996;75(6):1396-1403. DOI: 10.1177/00220345960750061101.

30. Uekusa S, Yamaguchi K, et al. Bonding Efficacy of Single-step Self-etch Systems to Sound Primary and Permanent Tooth Dentin. Oper Dent 2006;31(5):569-576. DOI: 10.2341/05-102. 